\title{
Oroantral Fistula Management and Treatment
}

\section{R. S. Rakhi Menon}

\begin{abstract}
Oroantral communication is a pathological communication between the oral and antral cavities. When oroantral communication is left open, epithelial tissue may develop namely oroantral fistula. The primary purpose is to close the communication and prevent sinusitis. OAF closures can be achieved using different flaps. The most widely employed flaps are vestibular flap, palatal flap and buccal fat pad flap. Traditional method includes tongue flaps, nasolabial flaps, palatal transposition flap etc.
\end{abstract}

Keywords: Anti Oxidants

\section{Introduction}

Oroantral fistula is a fistular canal covered with epithelia which may or may not be filled with granulation tissue or polyposis of the sinal mucous membrane, which frequently occurs because of iatrogenic oroantral communication between the oral cavity and the maxillary sinus as a result of extraction of maxillary lateral or premolar or molars (1). With the presence of a fistula the sinus is permanently open which enables the passage of infection from the oral cavity into the maxillary sinus and can result in the development of acute sinusitis.

Oroantral fistula and its management are important in the field of oral and maxillofacial surgery because of the anatomic position of the sinus and its connection with the maxillary teeth (1). A fistula might originate following removal of maxillary cysts, benign or malignant tumours or trauma. OAF is characterized by the presence of epithelium from the oral or antral sinus mucosa that if not removed could inhibit spontaneous healing (2)

\section{Clinical Features of Oroantral Fistula}

A purulent discharge may drip through the fistula. When the patient drinks water, he feels as though part of the liquid enters the nose from that side of the jaw. When the nostrils are closed with the fingers and the patient is asked to blow through the nose air flows from the fistula to the oral cavity. This is called as Valsalva test. A probe is usually used to detect the presence of fistular canal.

An oroantral defect is closed using a buccal flap with a thin layer of buccinator muscle, described by Baxhausen (5). A lateral or midalveolar fistulas located either laterally or in the middle of the alveolar process which is of small to medium size less than $1 \mathrm{~cm}$ can be closed using buccal sliding flap technique (6).A rotating gingivovestibular flap can also be used for the immediate closure of oroantral fistula $(7,8)$

Two vertical incisions are made to provide a flap of suitable dimension after cutting the communication edges and an incision removal of the epithelium lining the palatal mucosa behind the communication is required. A trapezoidal flap consisting of both epithelium and connective tissue is positioned over the defect from the buccal flap to the palatal mucosa by mattress sutures ( 7 )

Advantages: This procedure can be done even when the alveolar ridge is resorbed extensively. Buccal flap procedure
Oroantral fistula less than $2 \mathrm{~mm}$ diameter has the possibility of healing spontaneously (3). There is less possibility of spontaneous healing when the fistula is greater than $5 \mathrm{~mm}$ in diameter and has been present for more than 4 weeks (4)

\section{Surgical Management Of Oroantral Fistula}

\section{Buccal Flap}
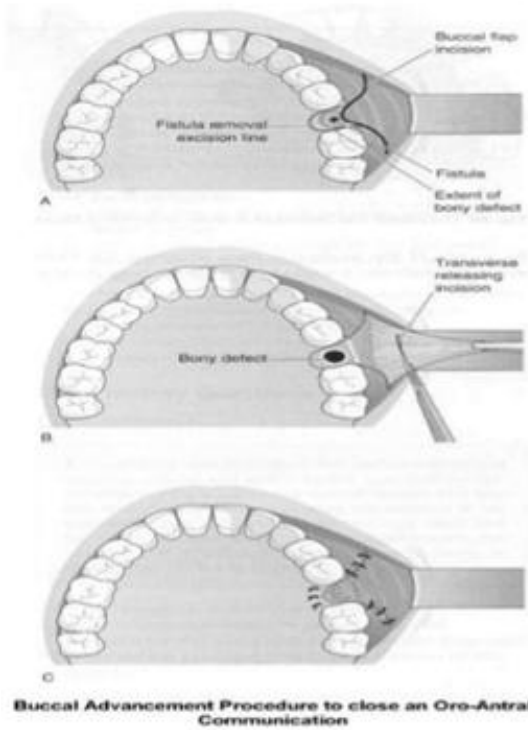

Buccal advancement flap-

Von rehrmann (1936); Berger

(1939)

can be done even when the fistula is located in a more mesial area (9).

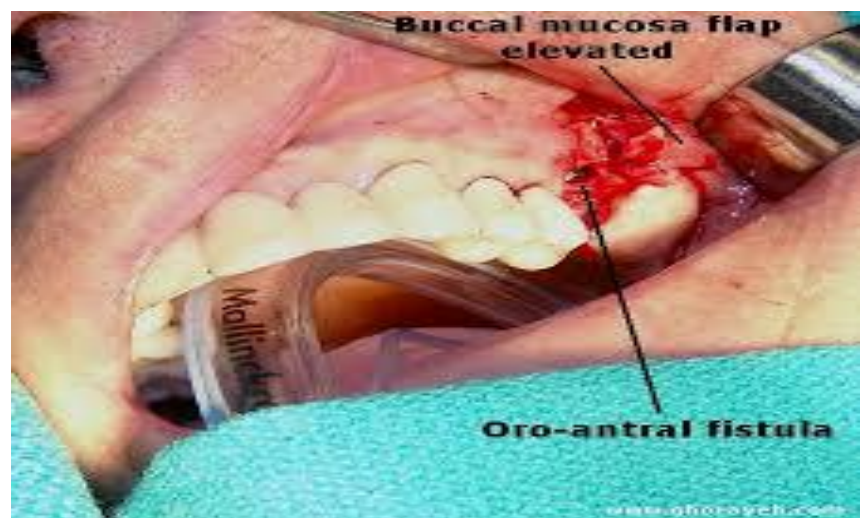




\section{International Journal of Science and Research (IJSR) ISSN (Online): 2319-7064}

Index Copernicus Value (2015): 78.96 | Impact Factor (2015): 6.391

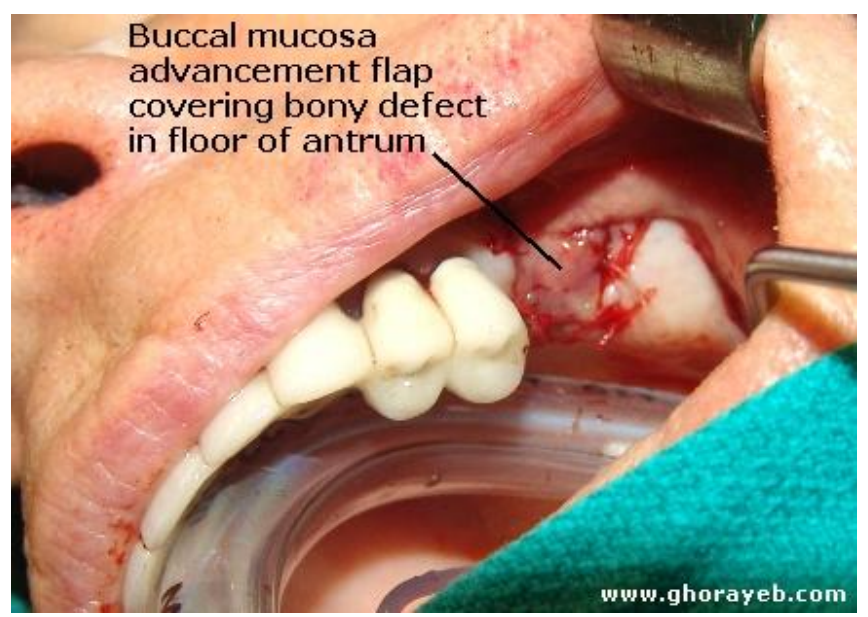

\section{Palatal Flap}

Ashley first described the procedure for oroantral fistula closure using palatal full thickness flap (10). Palatal rotation flap remains the choice for OAF closure because of the complete epithelisation of the palatal area after 4 weeks with no post operative complications. A palatal flap is marked with adequate width to cover the defect completely. A full thickness palatal mucoperiosteal flap is raised and rotated over the defect. A water tight closure is ensured by approximating both the buccal and palatal flaps (11)

\section{Advantages:}

Bone surface is preserved since the periosteum is not involved. Good vascularization. Adequate thickness and optimal tissue quality can be achieved (7).

Disadvantages: This type of flap is only indicated in the premolar area because excessive rotation can cause ischemia of palatal artery and necrosis (7)

However partial thickness flap avoid the occurrence of necrosis in wide oral antral fistulas caused by removal of cysts or tumours of large size.

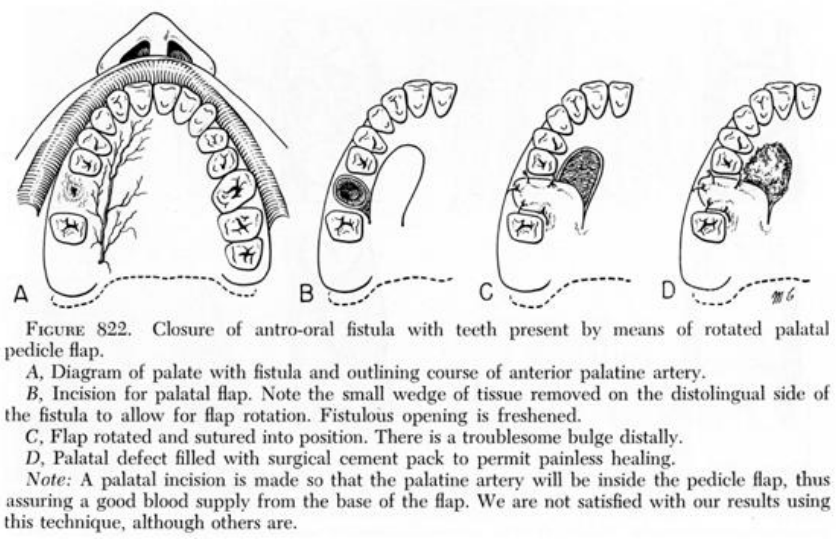

\section{Buccal Pad of Fat Flap}

The anatomy of buccal pad of fat flap was described by Stajcic, Rapidis and Tideman $(7,12)$. The buccal pad of fat is a simple lobulated mass covered by a thin layer or capsule located deeply along the posterior maxilla and the superior fibers of buccinator muscle $(13,14)$. The rapid epithelialisation of the uncovered fat is a characteristic feature of this type of flap (15). An incision of the posterior mucosa must be made in the area of the zygomatic buttress and then a slight incision in the periosteum and of the fascial envelope of the buccal pad followed by a gentle dissection with curved artery forceps which exposes the yellow colored buccal fat (7). Pedunculated type of buccal pad of fat flap is most commonly used.

Advantages: A good rate of epithelialisation and a low rate of failure (16)

Disadvantages: Mild reduction in the vestibular rate and incase of recurrence, a second surgery is required.

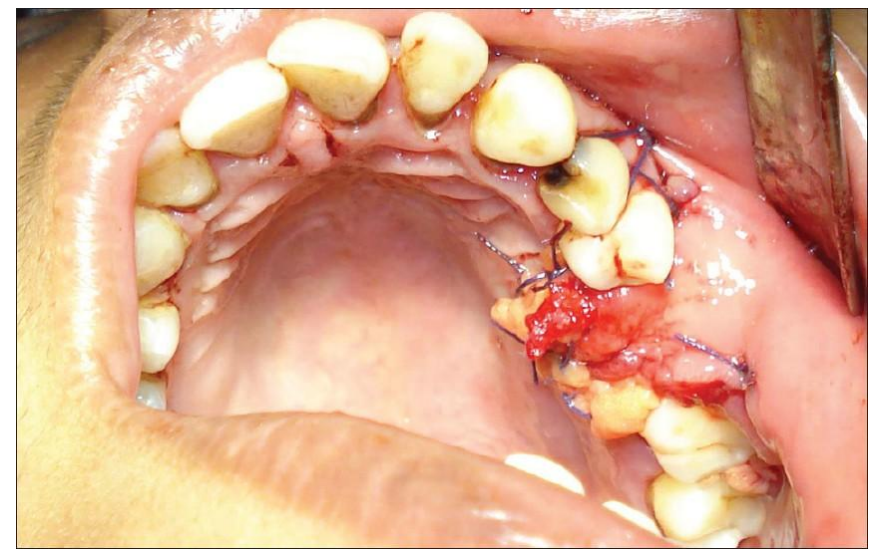

\section{Non-Surgical Management of an Oro-Antral Fistula in A Patient With HIV Infection}

The risk of post-extraction complications is higher in patients who are immunosuppressed compared to other patients with normal immune function. In such cases non surgical procedures are found out to be effective than invasive dental procedure to treat an oro antral fistula.

The oro-antral fistula was de-epithelialised under local anesthesia and the patient wore a surgical splint continuously, removing it only for cleaning, for an eight week period. Chlorhexidine gel was regularly applied to the fitting surface of the splint and the oro-antral communication. The patient was reviewed on a regular basis. This procedure resulted in resolution of the patient's symptoms within two weeks. Complete healing of the oroantral fistula was evident following eight weeks of wearing the surgical splint (17).

\section{Conclusion}

When choosing the surgical method of treatment of an oroantral fistula its location and size should be taken into consideration, also its relation to neighboring teeth, and the height of the alveolar ridge, duration, and existence or otherwise of inflamed sinus and the general health status of the patient. In the case of small perforations of the sinus, when there are no signs of sinusitis, spontaneous healing is possible, while in the case of larger perforations the chance of spontaneous healing is less. 


\section{International Journal of Science and Research (IJSR) \\ ISSN (Online): 2319-7064 \\ Index Copernicus Value (2015): 78.96 | Impact Factor (2015): 6.391}

Radical methods of surgical treatment remain as the choice in cases in which the fistula has lead to the sinus filling with hyperplastic mucous membrane, which has lost its function.

\section{References}

[1] Klara Sokler, Vanja Vuksan, Tomislav Lauc, Acta Stomatol Croat, Treatment of oroantral fistula Vol. 36, br. 1, 2002, 36:112-3

[2] Guven O.A clinical study on oroantral fistula. J Craniomaxillofac Surg 1998; 26:267-71

[3] Fickling BW. Oral surgery involving the maxillary sinus. Ann R Coll Surg Engl 1957;20:13-35

[4] Martenson. Treatment of Oroantral fistula, 1957

[5] Hanazawa et al Baumann A, Ewrs R. Application of the buccal fat pad in oral reconstruction. J Oral Maxillofac Surg. 2000;58:389-92

[6] Berger A. Oroantral openings and their surgical corrections. Arch otolaryngology 1939;130: 400-2

[7] Borgonovo et al, Surgical options in oroantral fistula treatment. J The open dentistry, 2012, 6, 94-98

[8] Baxhausen G. Closure of oroantral fistulae. Ann Otolaryngol 1939; 48: 632-8

[9] Amaratunga NA. Oro-antral fistulae. A study of clinical, radiological and treatment aspects. $\mathrm{Br} \mathrm{J}$ Oral Maxillofac Surg 1986;24: 433-7

[10] McGregor IA, Mc Gregor FM. Reconstructive techniques in intraoral surgery. In: McGregor FM, Ed. Cancer of the face and mouth. London: Churchill Livingst One 1986; pp. 412-9

[11] Tejraj P. Kale et al. Treatment of Oroantral Fistula using palatal flap- A case report and technical note. J. Int Oral Health, Vol 2 Is 3, 2010, 72-82

[12] Stajcic Z. The buccal fat pad in the closure of oro-antral communications: a study of 56 cases. J Craniomaxillofac Surg 1992; 20:193-7

[13] Fujimoto N, Nagura H, Enamato S. Grafting of the buccal fat pad into palatal defects. J Craniomaxillofac Surg 1990; 18: 219-22

[14] Hanazawa Y, Itoh K, Mabashi T, Sato K. Closure of oro-antral communications using a pedicled buccal fat pad graft. J Oral Maxillofac Surg 1995; 53: 771-5

[15] Haraji A, Zare R. The use of buccal fat pad for oroantral communication closure. J Mashhad Dent Sch Mashhad Univ Med Sci 2007;31 9-11

[16] Ferrari S, Ferri A, Bianchi B, Copelli C, Magri AS, Sesanna E. A novel technique for cheek mucosa defect reconstruction using a pedicled buccal fat pad and buccinator myomucosal island flap. Oral Oncol 2009;45: 59-62

[17] RM Logan, EA Coates. Non surgical management of an oro-antral fistula in a patient with HIV infection. Aust Dent J 2003;48:(4):255-258 